\title{
Digital customization of consumer investments in multiple funds: virtual integration improves risk-return decisions
}

\author{
Sesil Lim ${ }^{1} \cdot$ Bas Donkers ${ }^{1}$ Patrick van Dijl ${ }^{1}$ - Benedict G. C. Dellaert ${ }^{1,2}$ (D)
}

Received: 31 August 2019 / Accepted: 20 July 2020 / Published online: 11 August 2020

(C) The Author(s) 2020

\begin{abstract}
Digital technology in financial services is helping consumers gain wider access to investment funds, acquire these funds at lower costs, and customize their own investments. However, direct digital access also creates new challenges because consumers may make suboptimal investment decisions. We address the challenge that consumers often face complex investment decisions involving multiple funds. Normative optimal asset allocation theory prescribes that investors should simultaneously optimize risk-returns over their entire portfolio. We propose two behavioral effects (mental separation and correlation neglect) that prevent consumers from doing so and a new choice architecture of virtually integrating investment funds that can help overcome these effects. Results from three experiments, using general population samples, provide support for the predicted behavioral effects and the beneficial impact of virtual integration. We find that consumers' behavioral biases are not overcome by financial literacy, which further underlines the marketing relevance of this research.
\end{abstract}

Keywords Customization · Consumer decision making $\cdot$ Risk-return decisions $\cdot$ Digital marketing $\cdot$ Financial services $\cdot$ Online decision tools

\section{Introduction}

Recent advances in digital technology in the finance industry allow consumers to more easily invest in many different investment funds. For example, a recent report by the

Martin Schreier served as Guest Editor for this article.

Electronic supplementary material The online version of this article (https://doi.org/10.1007/s11747-020-00740-4) contains supplementary material, which is available to authorized users.

Benedict G. C. Dellaert

dellaert@ese.eur.nl

Sesil Lim

lim@ese.eur.nl

Bas Donkers

donkers@ese.eur.nl

Patrick van Dijl

pvandij1@gmail.com

1 Department of Business Economics, Erasmus School of Economics, Erasmus University, Rotterdam, P.O. Box 1738, 3000, DR Rotterdam, The Netherlands

2 Department of Marketing, Monash Business School, Monash University, P.O. Box 197, CaulfieldEast, Victoria 3145, Australia
Investment Company Institute estimates that, in 2018, $43.9 \%$ of all US households owned at least one mutual fund (Schrass and Bogdan 2018). Consumers can bypass financial advisors and customize their own investment portfolios by directly purchasing funds online. They can trade funds through online brokerage services and manage their financial capital using digital tools such as robo-advisors. Thus, digitization is helping consumers to gain wider access to highquality investment funds, to acquire these funds at a considerably lower cost, and to customize their own investments.

Consumers' increased digital access to investment funds also creates new challenges. Most prominently, consumers may end up making sub-optimal investment decisions (Barber and Odean 2001; Campbell 2016). One particularly important, yet also difficult, aspect of investment decision making is to accurately account for funds' risk-return ratios when deciding how to invest (Markowitz 1952; Sarin and Weber 1993). This is notoriously difficult for consumer investors (Lusardi and Mitchell 2017; Weber et al. 2005). Increasingly, digital technology is also suggested as a way to overcome such behavioral challenges. More specifically, research has shown that consumer investors can effectively be assisted in selecting their preferred risk-return levels by presenting them with interactive frequency-based distributions of investment returns ("risk-return distributions" for short) of an 
investment fund. These digitized risk-return distributions use simulation and graphic visualization to let consumer investors experience the relative frequency of different investment outcomes for a given fund (Goldstein et al. 2008; Kaufmann et al. 2013).

Our goal in this paper is to address another closely related challenge: consumers often face investment decisions that involve multiple funds, each with a different risk-return distribution (Anagol and Gamble 2013; Beshears et al. 2017). For example, consumers may participate in employer-sponsored retirement funds but also invest some of their own savings in separate, personal retirement funds, or parents may invest in target-date funds to support their children's future college fees and also invest in another fund to pay for home renovations after they become empty-nesters. Normative optimal asset allocation theory prescribes that investors should simultaneously optimize risk-returns over their entire portfolios when they make multiple investments (Markowitz 1952). However, consumer investors may find it difficult to integrate risk-returns over multiple funds because they mentally categorize different investment assets into different accounts (i.e., mental separation; Thaler 1985). In addition, consumers may neglect correlations between risk-return distributions of different funds (i.e., correlation neglect; Gubaydullina and Spiwoks 2015; Kallir and Sonsino 2009; Kroll et al. 1988). Both behavioral effects should lead consumers to make suboptimal investment decisions, which expose them to excessive risks due to under- or over-diversification.

It is as yet unknown if interactive investment risk-return distributions can also be used to help consumers overcome this challenge. We predict that, due to the complexity of choosing multiple funds, consumers' behavioral biases will persist. Therefore, we propose and test a new choice architecture to support consumers who invest in multiple funds. In particular, we propose to virtually integrate the different funds in one (integrated) fund that is presented to consumers. Virtual integration transfers the difficult task of combining the riskreturn distributions of different funds to the digital environment, and we predict that this will help consumers achieve better investment decision outcomes.

We implement the new choice architecture and test our prediction in three incentive-compatible experiments using general population samples. The experiments presented consumers with online interactive investment risk-return distributions that allowed them to customize their own preferred portfolios from two investment funds. The distributions of investment funds were presented to consumers either separately or in a single - virtually integrated - fashion. We also measured the financial literacy for consumers (Lusardi et al. 2010).

Our research contributes to the literature in three important ways. First, we propose two behavioral decision effects (mental separation and correlation neglect) that occur when consumers invest in multiple funds. We find that these behavioral effects do indeed occur, even when consumers use newly proposed interactive investment risk-return distributions (Goldstein et al. 2008). Second, we test and find support for the proposed positive impact of virtual integration of multiple investment funds on consumer investment decision outcomes, based on a well-defined objective outcome criterion. Third, we find that consumers' behavioral biases when investing in multiple funds are not predicted by financial literacy, which underlines the fact that even expert consumer investors can benefit from the proposed virtual fund integration on financial investment firms' websites. In a managerial simulation based on our empirical results, we show that these biases lead to a total loss of over $1 \%$ of the invested amount in only a five-year period.

\section{Investment decisions with multiple funds}

\section{Normative framework}

Financial portfolio theory provides a normative framework for selecting a single optimal investment portfolio for an investment fund (Markowitz 1952). The theory assumes that investors are rational and maximize the economic value of their investments. They are risk-averse toward the returns on their investments in that they wish to obtain both higher means and lower variances (i.e., risk). Therefore, when making investment decisions, investors trade increases in expected returns against greater risks. When asset returns are normally distributed, a set of Pareto-optimal asset portfolios is defined that achieves the highest return for a given level of risk (i.e., the Markowitz efficient frontier; see Fig. 1). The risk-return ratio of different asset portfolios can be compared using the Sharpe ratio that expresses for a given level of risk, the portfolio's returns to a benchmark standard (Sharpe 1966). The investment fund's challenge is to find the portfolio of risky assets that maximizes the Sharpe ratio within the boundaries of the fund's investment strategy (i.e., the tangency portfolio; see Fig. 1). Since different funds may have different strategies (e.g., emphasizing sustainability or focusing on a certain region or industry), the selected portfolio may also differ between funds.

Under this framework, financial firms can then offer individuals customized efficient asset allocations by differentially combining the firm's investment fund's portfolio (the portfolio of risky assets that maximizes the Sharpe ratio) and a riskfree asset to obtain a desired personalized risk-return combination for each investor (Tobin 1958). The firm's task can be separated into two steps: first, compose the portfolio of risky assets that maximizes the Sharpe ratio within the boundaries of its investment fund's strategy (e.g., sustainable long-term growth); second, select consumer investors' personal allocations of their investments in the tangency portfolio and the 
Fig. 1 Customizing a single investment fund with heterogeneous risk-return preferences. Note. $R^{f}$ represents the risk-free return. $R_{\text {low }}$ and $R_{\text {high }}$ are examples of points on the optimal CAL for a relatively more and relatively less risk-averse consumer investor, respectively

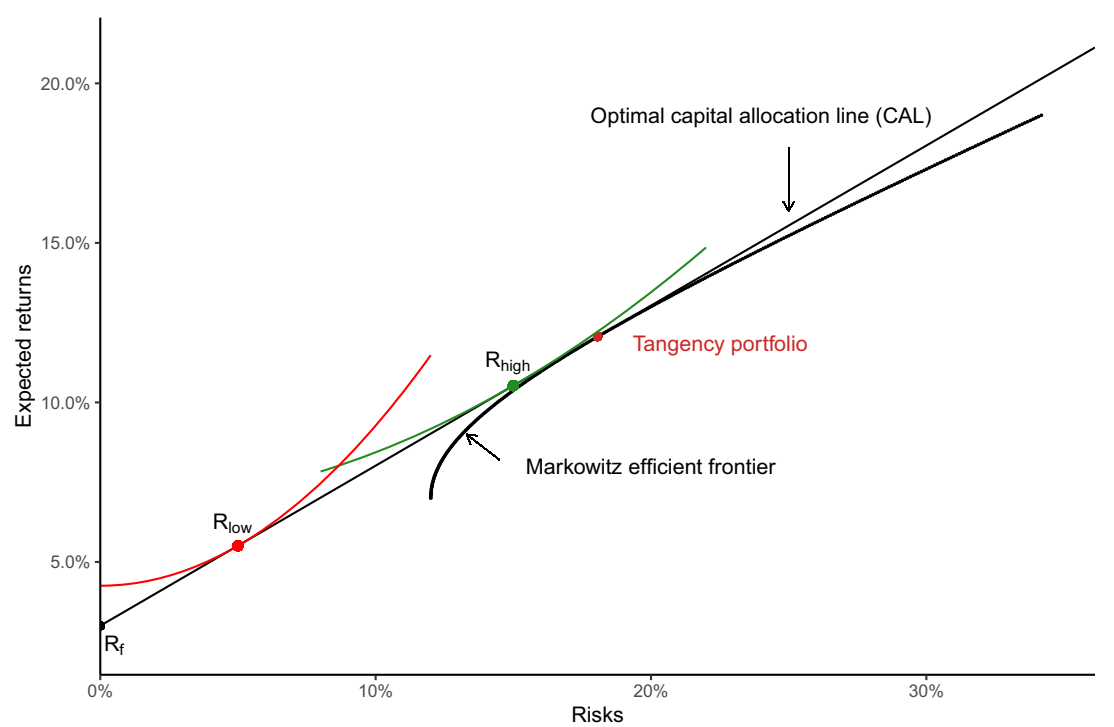

risk-free asset to match their risk-return preferences (these are points on the optimal capital allocation line [CAL]; see Fig. 1). This second step is typically informed by asking investors a set of risk preference elicitation questions (Holt and Laury 2002), after which the firm suggests the best matching distribution. However, an interactive customization process has recently been proposed in which consumers directly select their resulting distributions (Goldstein et al. 2008; see also the next section on digital customization). Figure 1 illustrates two optimal portfolios for individuals who have a relatively high risk aversion and a relatively low risk aversion $\left(\mathrm{R}_{\text {low }}\right.$ represents the more risk-averse person with a low-risk and low-returns portfolio, and $\mathrm{R}_{\text {high }}$ represents a less risk-averse person with high-risk and high-returns portfolio). Thus, depending on their risk-return preferences, consumer investors can be placed at different risk-return portfolios on the CAL running through the risk-free return $\left(\mathrm{R}_{\mathrm{f}}\right)$ and the tangency portfolio.

Now, consider a consumer investor who participates in multiple investment funds (e.g., two retirement funds, or an education fund and a general investment fund) and each investment fund allows investors to customize the risk-return level according to their own preferences. Under the assumption of a multivariate normal distribution of asset returns, the risk-return distribution of the combination of the two investment funds is defined by the mean and standard deviation of their joint distribution. Thus, consumer investors are faced with the additional cognitive challenge of integrating the mean returns as well as the variances (risks) of the different investment funds in which they participate.

Normatively, performing this integration is important because investors can improve their overall investment portfolios by properly balancing their investments in different funds when the investments in the funds are not perfectly correlated
(Markowitz 1952; Blume and Friend 1975; Goldstein et al. 2008). This strategy of diversification allows investors to obtain a higher risk-return ratio than investing in a single fund. Importantly, the benefit of diversification depends on the correlation between the return distributions of the different funds (in the extreme, if the funds are perfectly correlated, no benefits arise from diversification, while with lower correlations, the benefits increase). Thus, investing in multiple funds requires investors to accurately consider the correlation between the returns of the different investment funds.

\section{Proposed behavioral effects}

We propose two behavioral effects that hinder consumer investors in cognitively integrating different investment funds. First, the theory of mental accounting suggests that individuals may compartmentalize their investments into mental accounts and evaluate potential gains and losses for each mental account separately (Shefrin and Statman 2000; Thaler 1985). For example, recent research suggests that individuals may set up mental accounts as a cognitive strategy to protect themselves against spending money from certain (targeted) investments on alternative purposes (Brendl et al. 1998; Sussman and O'Brien 2016; Zhou and Pham 2004). We anticipate that consumer investors likely also classify different investment funds into different mental accounts, and will, therefore, only partially integrate the risk-returns over different funds (Siebenmorgen and Weber 2003). Hence, obtaining an optimum risk-return over multiple funds is difficult for consumer investors due to the mental separation of these funds that hinders a fully integrated evaluation during the decision process (Kaufmann and Weber 2013).

Second, even if consumer investors mentally combine the different risk-return distributions, they still face the challenge 
of accounting for the correlations between these distributions. Recent research reports that consumers tend to neglect correlations that exist between different sources of information. For example, in the context of elections, voters have been found to underestimate the correlation between their information sources (Levy and Razin 2015). These results were also shown in controlled lab experiments that examined updating beliefs on news items, where many individuals were found to treat correlated information as independent information (Enke and Zimmermann 2019). There is emerging evidence that consumer investors also tend to neglect correlations when deciding how to allocate assets to funds (Eyster and Weizsäcker 2016; Kallir and Sonsino 2009). Thus, we anticipate that both mental accounting and correlation neglect will contribute to the difficulty consumer investors face when making investment decisions intended to accurately integrate multiple investment funds.

Financial literacy is a potentially important moderator of these proposed behavioral effects. When consumers are more financially literate, they are more capable of performing complex financial investment decisions because they hold a deeper understanding of the factors that drive investment performance (Lusardi et al. 2010; Lusardi and Mitchell 2017). However, even experienced retail investors may lack the level of financial literacy to properly make complex investment decisions (Barber and Odean 2001; Campbell 2016; Fernandes et al. 2014; Van Rooij et al. 2011). Therefore, it is an open question, empirically, whether or not consumer investors with greater financial literacy are less susceptible to the proposed behavioral effects of correlation neglect and mental separation of investment funds.

\section{Digital customization with interactive outcome-based risk-return distributions: From single to multiple investment funds}

\section{Customizing a single investment fund}

Most current approaches used by financial firms to match investments to individuals' risk-return preferences do not allow consumer investors to customize their own risk-returns. Instead, these approaches first elicit an investor's preferences that are then used by the firm as input for personalized investment advice. For example, one well-known approach is the multiple lottery choice method (Dohmen et al. 2011; Holt and Laury 2002). This approach introduces a series of choices with an increasing risk-return payoff. The higher an individual's risk aversion, the higher the expected return needs to be for the risky lottery to be acceptable, thus providing a measure of the individual's risk aversion. This approach can be used to personalize investments to individuals' risk-return preferences, but it still places a relatively high burden of understanding on the individual (Alserda et al. 2019).

When it comes to customization, a straightforward approach is to ask individuals directly to allocate dollar amounts or wealth shares directly to the investment fund and a risk-free asset (Van Rooij et al. 2007). This approach mimics simple approaches in the mass-customization of manufactured products, where consumers can directly choose product components to compose their own preferred designs (Dellaert and Stremersch 2005; Franke et al. 2010). However, the central role of risk-returns in financial investments places specific requirements on customization interfaces. The direct choice of an investment fund allocation still assumes the consumer investor has a high level of understanding about the implications of different risk-return levels; this is likely unrealistic (Van Rooij et al. 2011).

Therefore, we employed an interactive online tool inspired by the Distribution Builder (DB) (Goldstein et al. 2008) to allow consumer investors to customize their investments. The DB was developed based on the psychological insight that individuals are best able to understand risks when they are presented as frequencies (Fagerlin et al. 2011). We designed an easy-to-use online version that graphically presents the risk-return information of a fund as a histogram. This histogram is composed of 100 markers that each represent a possible outcome, with each outcome having an equal probability of occurring. Consumers can determine the risk level of the fund by moving a slider, and the tool automatically presents the return distribution for the corresponding risk level (see Fig. 2). Thus, the tool allows consumer investors to intuitively grasp the impact of a decision on the risks and returns of their investments and supports them in their tradeoff between risks and returns (Donkers et al. 2013; Goldstein et al. 2008). After customizing their preferred risk-return level, consumers experienced the consequences of their decisions by sequentially viewing five possible outcomes so that they could better understand their selected risk-return levels (Kaufmann et al. 2013). Consumers can then adjust their selected risk-return distribution and experience additional draws as often as they wish.

The interactivity embedded in this approach supports users' understanding of two important aspects of investment decisions: understanding the risk embedded in the outcome distribution and realizing the link between risks and returns in the distribution. While using the tool, users become aware of the link between risk and return through an interactive process, as they could directly see that accepting an increase in the dispersion of the outcomes (greater risk) also shifts the distribution toward a higher expected return. Understanding of these return distributions is improved by showing users repeated samples from the distribution. Sampling of outcomes has been shown to improve risk understanding (Sedlmeier and Gigerenzer 2001). 


\section{a Separate condition (fund by fund)}

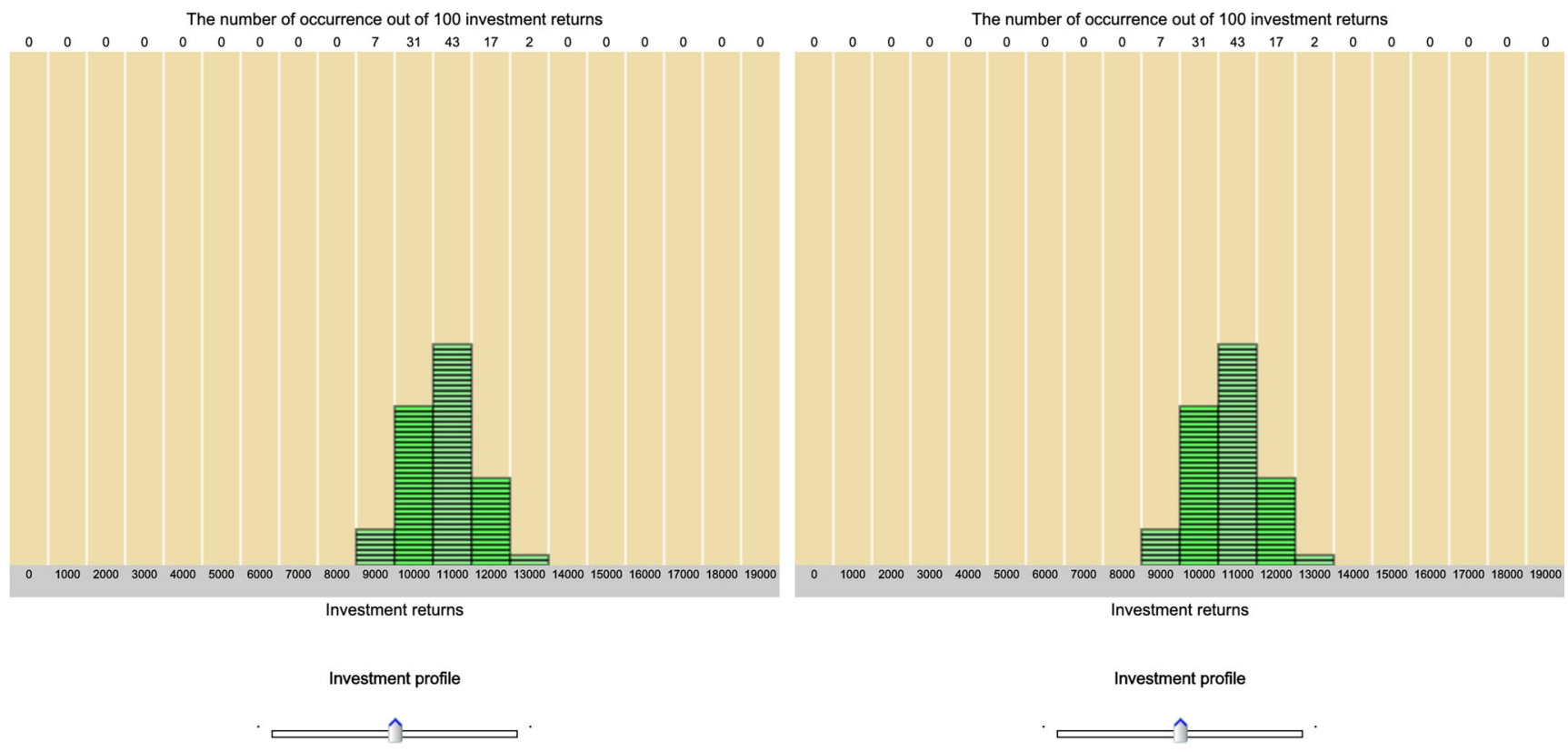

\section{b Virtually integrated condition}

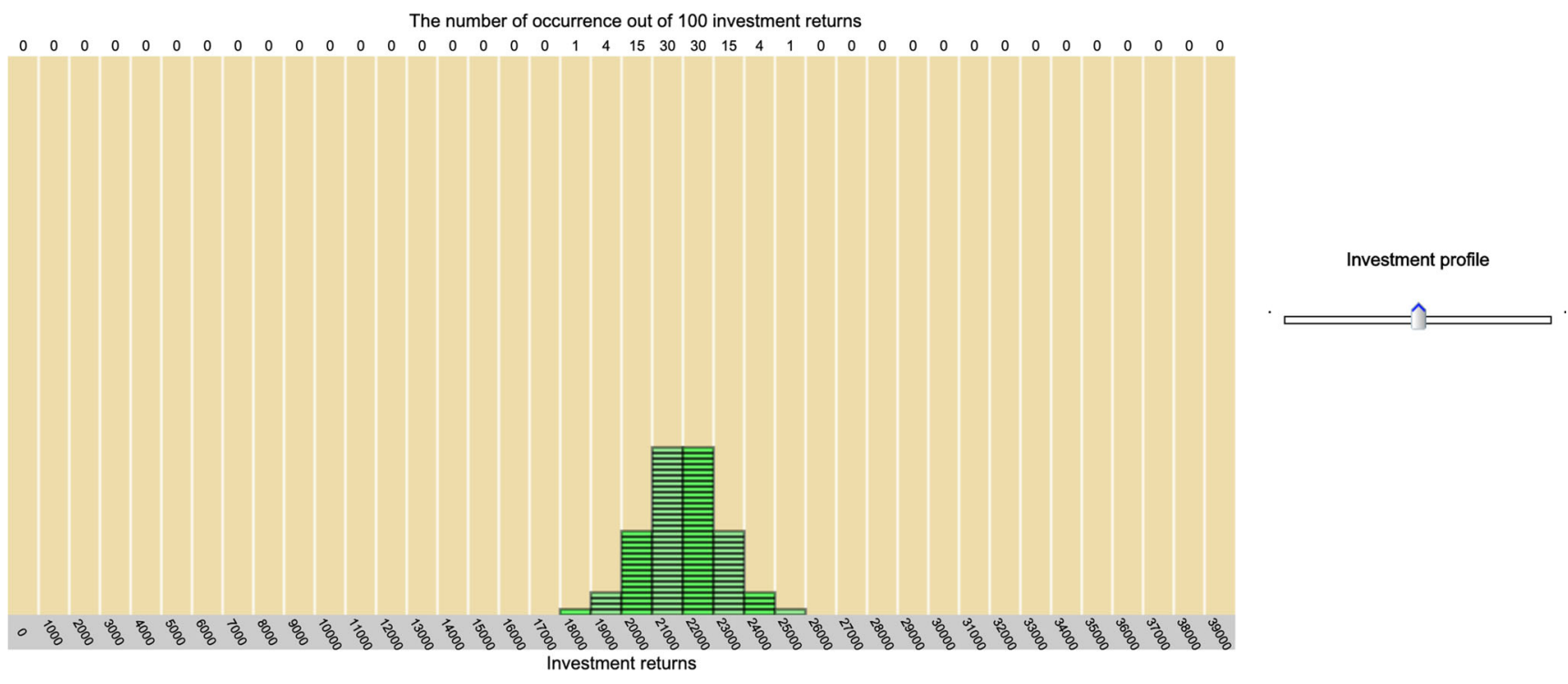

Fig. 2 Separate and virtually integrated investment decision choice architectures

\section{Customizing multiple investment funds: The benefit of virtual integration}

While the interactive presentation of risk-return distributions can strongly improve consumer investors' understanding of these distributions, we predict that such increased understanding is distribution specific and unlikely to help investors overcome the challenges that arise when choosing multiple correlated investments. The proposed behavioral effects of mental accounting and the tendency towards correlation neglect are likely to hinder the discovery, and subsequent accurate incorporation of correlations between different distributions is cognitively demanding.

To overcome these behavioral challenges, we look more broadly to the literature on mass-customization. While this literature focuses strongly on manufactured productswhich are different from financial investments in many respects - consumers also face the challenge of integrating 
different product components into one overall design. One particular solution, which is commonly proposed in the mass-customization of manufactured products, is to provide consumers with virtual toolkits that allow them to virtually experience the end-products they have composed before making their final decisions (Randall et al. 2005; Von Hippel and Katz 2002). For example, when selecting the different components of a running shoe on NikeID, consumers are shown their resulting shoe designs in a virtual representation that helps them judge the total result of the choices they made. Thus, the online system aids consumers by integrating the separate components into an overall product.

Extending this line of reasoning, we propose that consumers should benefit from a new choice architecture that virtually integrates the multiple investment funds into one combined investment fund. Doing so will facilitate their decisionmaking process by already combining the multiple, correlated risk-return distributions into one joint distribution. Thus, in an online interactive tool, consumer investors can be presented with the distribution of returns of one optimally combined fund. In this virtually integrated fund, the risks and returns of the underlying investment funds are combined into one joint riskefficient portfolio that accounts for the correlations between the distributions of the different funds. The tool ensures an optimal asset allocation between the different investment funds, even when there are multiple, likely correlated, assets.

To date, only two papers have investigated the difference in investor decisions between separate and integrated risk-return distributions across multiple assets. In contrast to our research, this previous work has focused on investor risk-return preferences as the dependent variable, and its aim was not to propose an approach to overcome consumer decision challenges. The findings in this previous research are mixed. Anagol and Gamble (2013) found that individuals increase their risk-taking when presented with combined investments, compared to separate investments, while Beshears et al. (2017) found no effect of information aggregation on risktaking in investment decisions. Given the subjective nature of risk-return preferences, it is not clear whether the observed shifts improved or deteriorated consumer investors' decision outcomes.

To demonstrate this distinction, Fig. 3 visualizes an investor's possible combined investment decisions in the separate and virtually integrated conditions in the risk-return space. Every point in the gray area reflects a risk-return portfolio consisting of two funds that can be obtained with separate investment fund decisions. The dark line reflects the (smaller) set of all possible risk-return profiles that can be chosen in the virtually integrated condition that assists the consumer. This line is identical to the optimal CAL that provides the best possible portfolio for each given level of risk (or expected return). Thus, when making separate decisions, consumer investors may choose a wide range of inefficient portfolios (i.e., portfolios that are strictly below the optimal CAL) that they are prevented from choosing in the virtually integrated condition.

To determine the objective benefits of the virtual integration of funds, we propose to determine how far investors are removed from the optimal CAL when they decide on the riskreturn levels for investment funds separately. We quantify this deviation from optimality in two ways. First, we determine the investment portfolio with the highest return at the risk level selected for the separate choices (i.e., point $\mathrm{S}^{\prime}$ in Fig. 3). The difference between this portfolio and the expected returns actually selected in the separate condition reflects the loss in expected returns from making the separate choice compared to the optimal integrated return decision. Second, we determine the portfolio that has the lowest risk for the same
Fig. 3 Consumer investors' possible choices in the risk-return space: Separate versus virtually integrated decisions. Note. S* represent the optimal choices that have the lowest risk for the same expected returns as an investor's separate choices $\mathrm{S} ; \mathrm{S}^{\prime}$ represent the optimal choices with the highest returns for the same risk level as an investor's separate choices $\mathrm{S}$

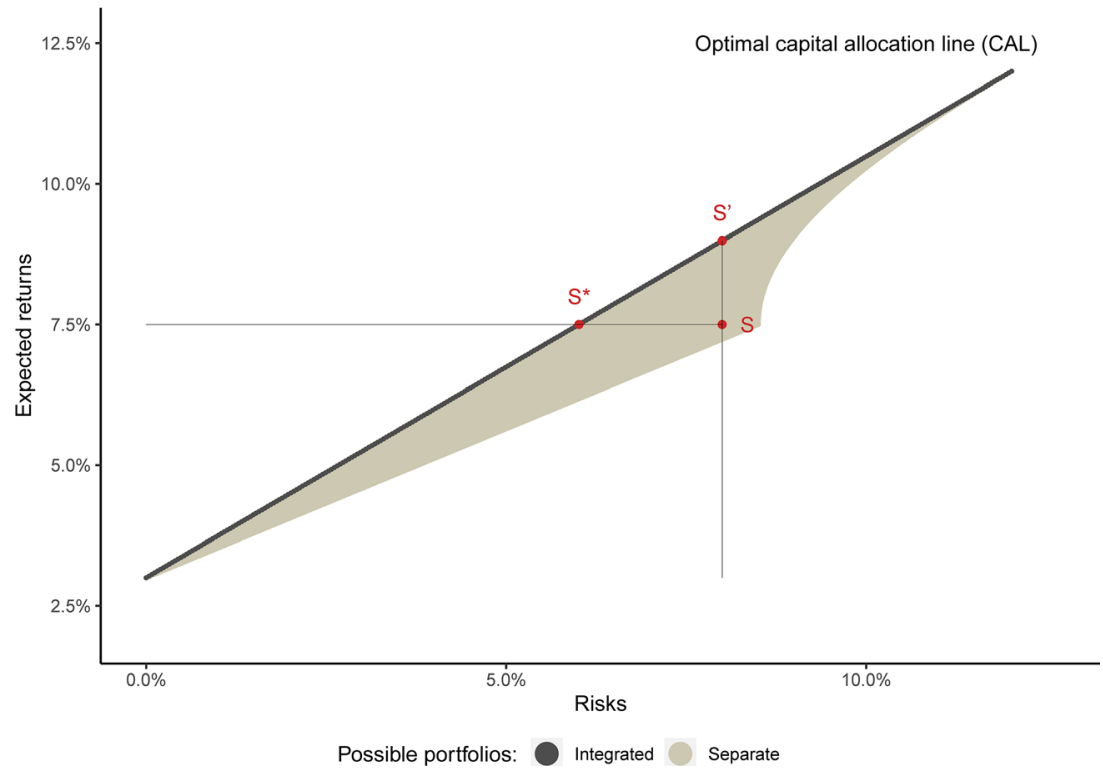


expected return as the consumers' separate choices (i.e., point $\mathrm{S}^{*}$ in Fig. 3). The difference between this risk and the risk actually selected in the separate condition reflects the excessive risk that participants expose themselves to.

\section{Experiment 1: Consumer investment decisions with identical correlated investment funds}

The objective of Experiment 1 was to test our main prediction that consumers' separate investment decisions for correlated funds can be improved by virtually integrating these funds. Participants customized two investment funds using an interactive risk-return distribution, both in a separate and a virtually integrated condition. They were presented with two positively correlated, but otherwise identical, risk-return distributions.

\section{Method}

Experimental design The experimental design was a mixed 2 (separate vs. virtually integrated presentation - within subjects) by 3 (investment goal 1, goal 2, and both goals 1 and $2-$ between subjects) design. All participants made investment decisions in the separate and virtually integrated investment fund conditions, and the order of presentation of these tasks was randomized. In addition, participants were randomly assigned to one of three investment goal conditons, in which they were told that they were investing to save up for a new kitchen (goal 1), a car (goal 2), or both (goals 1 and 2). These conditions were introduced to allow for generalizability across different investment goals. However, as the conclusions of the analyses were not affected by these investment goals, ${ }^{1}$ we combine the three goal conditions in the further discussion of the results of the experiment.

Participant task and customization interface In the experiment, participants made a hypothetical decision in which they were asked to invest a total amount of $€ 20,000$, split equally between two investment funds. They could customize the risk-return distribution for their investments. To do so, they were presented with an interactive online tool that allowed them to select their preferred risk-return distribution for the investment fund by means of an easy-to-use slider (see Fig. 2). All participants made a choice in both the separate and virtually integrated conditions for these two funds. At the start of the experiment, participants watched an instructional video that explained how to use the interactive risk-return tool.

\footnotetext{
${ }^{1}$ The effects of investment goals on participants' decisions were not significant both in terms of the main effect and the interaction effect with the integration conditions.
}

Then, they continued to the actual tool and selected their preferred risk-return distribution in each of the two conditions. They could explore as many risk-return options as they wanted before making their decisions. To assure participants' understanding of the impact of the risk-return distribution they selected, participants experienced five possible outcomes from the selected distribution after making their (initial) choices. After this, participants were given the opportunity to change their selected risk-return distribution and experience additional samples until they were ready to make their final decisions. Once they had completed their investment choices, participants then answered a series of background questions.

The financial market model behind the interactive tool was configured based on normally distributed returns, with distribution parameters based on the distribution of annual returns of the S\&P 500 from January 1988 to December 2017 (mean: $12.2 \%$; standard deviation: $17.1 \%$, retrieved from Shiller 2018). The risk-free rate of return is set at 3.0\%. Participants could hence choose from a broad range of risk-return combinations, as the tool enables them to combine the risky and riskfree assets to move freely over the CAL (i.e., the set of opti$\mathrm{mal}^{2}$ investment portfolios). There was a positive correlation between the returns of the two funds (Pearson correlation coefficient $\rho=0.6)^{3}$

Participants received a reward of $€ 2.35$, plus a possible bonus payment. The bonus payment was implemented to make the experiment incentive aligned, and participants were informed that one in every 200 participants would be randomly selected as a "winner" to receive an additional reward. More specifically, for each winner, the risk-return distribution from one of the two decision tasks they completed was randomly selected, and a draw from the participant's selected return distribution was obtained. The winners received $1 \%$ of the randomly drawn investment outcome from their riskreturn distribution (i.e., about $€ 200$ ).

Background questions Data were collected on a number of background variables from each participant (for a complete overview of all questions, see Web Appendix 1). Financial literacy was assessed based on the advanced financial literacy questions developed by Van Rooij et al. (2011). In addition, participants' subjective risk preference was

\footnotetext{
${ }^{2}$ Optimality is defined as providing the highest expected return for the given level of risk (variance), or its equivalent, the lowest risk given a specific expected return.

${ }^{3}$ Previous empirical research has found that the realized correlation of stock returns is mostly concentrated on the positive values. For example, the Pearson correlation coefficient for daily returns of 57 stock markets during 2005 to 2014 had a mean of 0.36 (with a range of -0.03 to 0.95 ; Wang et al. 2018). Thus, in this study, we focus on the case of a positive correlation between fund returns. The value of the Pearson correlation coefficient in our study was set in line with the values set in previous experimental research (e.g., 2/3 in Kallir and Sonsino 2009; and 0.6 in Laudenbach et al. 2017).
} 
measured using two questions: a) participants were asked about their risk preferences regarding financial investments on a 1 (not willing to take any risk) to 7 (willing to accept substantial risk to potentially earn a greater return) scale (Kaufmann and Weber 2013), and b) participants' general preferences for risks were measured on the scale from 1 (not at all willing to bear high risk) to 4 (very willing to bear high risk for earning a high expected return) scale (Dorn and Huberman 2005; Anagol and Gamble 2013). An understanding score was obtained for each participant by asking four questions to test whether they infer the risk or expected returns under the given sample distribution correctly. A measure of cognitive ability was obtained, based on the cognitive reflection test of Frederic (2005).

Two more measures were included to explore consumers' awareness of the correlations between the distributions and their tendency to form separate mental accounts for different investment funds. To measure how well participants were aware of the correlation between the investment returns, we employed the following approach. Based on their experiences with the funds in the tool, participants were asked to infer what the most likely outcome of one fund would be when they knew that the other fund had returned a loss on the investment. Given the positive correlation between the returns of the two funds, the correct answer is a loss, and we registered whether their answers were correct or not. Lastly, we measured participants' likelihood to treat multiple wealth accounts as separate mental accounts. Specifically, participants were asked to assess how likely (on a scale from 0 to 10 ) they were to transfer money from one account to another account when each account had a different investment goal.

Finally, participants' age, annual income, gender, and level of education were also measured, which have been shown to affect financial decisions (Anagol and Gamble 2013; Bateman et al. 2016; Kaufmann and Weber 2013; Van Rooij et al. 2007).

Sample A sample of 598 participants was recruited in the Netherlands to be largely representative of the Dutch general population. Participants were recruited by a market research agency using their online panel and were paid for participation in the task. The average age of participants was $47.84,53.8 \%$ were female, and their average annual income, before tax, was $€ 37,318$ (see Appendix 1 for details).

\section{Results}

To investigate the effect of virtually integrating the two investment funds, we compared the risk-return profiles of the investment portfolios that were chosen by participants in the virtually integrated condition (integrated condition) and those chosen in the separate condition (separate condition). Table 1
Table 1 Returns and risks of participants' chosen investment portfolios in Experiment $1^{£}$

\begin{tabular}{lll}
\hline & Separate & Integrated \\
\hline Expected return & $8.4 \%(1.8 \%)$ & $7.9 \%(2.1 \%)$ \\
Risk & $9.2 \%(3.0 \%)$ & $8.3 \%(3.6 \%)$ \\
Loss in returns in separate condition & $0.04 \%(0.08 \%)$ & \\
Excessive risk in separate condition & $0.07 \%(0.13 \%)$ & \\
\hline
\end{tabular}

${ }^{£} N=598$. All values are significantly different between the separate and virtually integrated conditions $(p<.05)$. Standard deviations in parentheses. Table presents average values over three investment goal conditions

reports the expected returns and risks for the two conditions. ${ }^{4}$ We find that participants' investment decisions differed significantly between the virtually integrated and the separate conditions on both the risks and the returns that they selected $(p<.05)$. More specifically, participants selected distributions with higher risk-returns in the separate condition $(9.2 \%$ risk and $8.4 \%$ return) than in the virtually integrated condition ( $8.3 \%$ risk and $7.9 \%$ return).

Selecting a higher expected risk-return level is not necessarily a suboptimal outcome, as investors can move along the CAL. Thus, whether or not this is the case depends on the specific points that are selected in the separate investment funds. Therefore, we evaluate participants choices based on the two proposed objective decision outcome measures of loss in returns and excessive risks (see Fig. 3). We find that participants, on average, lose $0.04 \%$-points in terms of their loss in returns and take $0.07 \%$-points of excess risk due to their mistakes in the separate investment decision (see Table 1). Given that the performance measures for separate choices cannot exceed those in the integrated condition (that are opti$\mathrm{mal})$, it is not surprising that these inefficiency values are also significantly different from zero $(p<.05)$.

To investigate if financial literacy attenuates the negative effect of making separate investment fund choices, we regressed the inefficiency measures of investors' separate investment decisions on financial literacy and a number of other participant characteristics. The estimation results of two robust linear regression models, one for loss in returns and one for excessive risks, reveals that financial literacy does not protect participants from the behavioral challenge of integrating correlated investment funds when making investment decisions. Other variables did not affect consumers investors' inefficiency either, with one exception: we find that participants with a higher incomes tended to choose less efficient portfolios when choosing funds separately, both in terms of loss in returns $(\beta=.001 ; p<.05)$ and in terms of excessive

\footnotetext{
${ }^{4}$ Returns are yearly returns. Risks are the standard deviations of the returns. A test of differences across the three investment goal conditions revealed no significant differences.
} 
risk $(\beta=.002 ; p<.05)$. We also investigated if different investment goals, greater understanding and cognitive ability, and the exploratory measures of correlation awareness and tendency to form mental accounts impacted consumer investors' decision performance, but none had a significant effect. These findings further underline that the behavioral challenges of integrating different investment funds are stable between consumers and goal conditions and difficult for consumers to overcome by garnering additional financial insight. The full analysis results are provided in Web Appendix 2.

\section{Discussion}

The results from Experiment 1 provide clear support for the fact that consumer investors experience behavioral decisionmaking challenges in integrating separate investment fund decisions and that virtual integration of funds helps them achieve objectively better decision outcomes. We also find that financial literacy does not attenuate this difficulty effect and that more financially literate consumer investors benefit from the virtual integration of multiple funds. In the experiment, we included two correlated, but otherwise identical, investment funds. This created a relatively simple, in the context of multiple investment funds, decision task. Hence, the results of this experiment provide a conservative lower bound on the biases that may arise when consumers make separate investment decisions and of the benefits of the virtual integration of funds. We further extend this analysis in Experiment 2 by investigating decisions with different risk-return distributions. $^{5}$

\section{Experiment 2: The joint impact of different distributions and correlation}

The objective of Experiment 2 was twofold. First, it aims to extend Experiment 1 to a more realistic setting of two investment funds with different risk-return distributions. Second, it introduces a new condition of no correlation between the two different investment funds. This condition allows us to disentangle a "baseline" separation effect in the no-correlation condition (that cannot be explained by correlation neglect) from the joint mental separation and correlation neglect effects in the correlated condition, thereby providing further insights into the proposed behavioral drivers of consumer investors' suboptimal decision outcomes.

\footnotetext{
$\overline{5}$ The biases can be stronger if there are more than two investment funds included in the experiment as this increases the complexity in the decision. However, such a case was not considered in our research. Since the main purpose of this paper is to argue the benefit of the virtual integration of funds, we believe providing pieces of evidence based on the decision on two investment funds fulfills the goal.
}

\section{Method}

Experimental design The experimental design was a mixed 2 (separate vs. virtually integrated - within subjects) by 2 (no correlation vs. positive correlation - between subjects) design. As in Experiment 1, all participants made investment decisions in the separate and virtually integrated investment fund conditions, and the order of the presentation of these tasks was randomized. However, in contrast to Experiment 1, participants were randomly assigned to one of two correlation conditions: one in which no correlation existed between the two investment funds (Pearson correlation coefficient $\rho=0$ ), and one in which a positive correlation existed $(\rho=0.6){ }^{6}$

Participant task, customization interface, and background questions In Experiment 2, participants were asked to invest a total amount of $€ 200$, split equally between two investment funds. The procedure followed was the same as in Experiment 1. Participants could again customize the risk-return distribution for their investments using the same interactive riskreturn distribution tool. However, in contrast to Experiment 1 , one investment fund was set to a higher risk-return distribution (mean: 13\%; standard deviation: 20\%) than the other (mean: 7\%; standard deviation 12\%) (see the left- and righthand distribution, respectively, in Fig. 4).

This experiment was also incentive aligned through a bonus payment. Participants received $€ 2.35$ as a reward for their participation, and an additional bonus was paid to one randomly selected participant out of every 200 participants. These winners received an actual amount drawn from one of the two actual risk-return distributions that they had selected. No specific investment goal was mentioned to the participants.

The same background variables were collected from participants as in Experiment 1, with the exception of the separate mental separation question that was related to the different investment goals. Data on participants' age, annual income, gender, and the level of education were also collected.

Sample A sample of 310 participants in the Netherlands were recruited to be largely representative of the Dutch general population. Participants were recruited by a market research agency, from their online panel. The average age of participants in this sample was $46.72,49.0 \%$ were female, and their average annual income, before tax, was $€ 42,149$ (see Appendix 1 for details). As a result of the random assignment, 152 participants made decisions in the no-correlation condition, and 158 made decisions in the positive correlation condition.

\footnotetext{
${ }^{6}$ The total data collection also included a third condition where the correlation was negative. However, since we address this condition separately in Experiment 3 we do not include it here as well.
} 

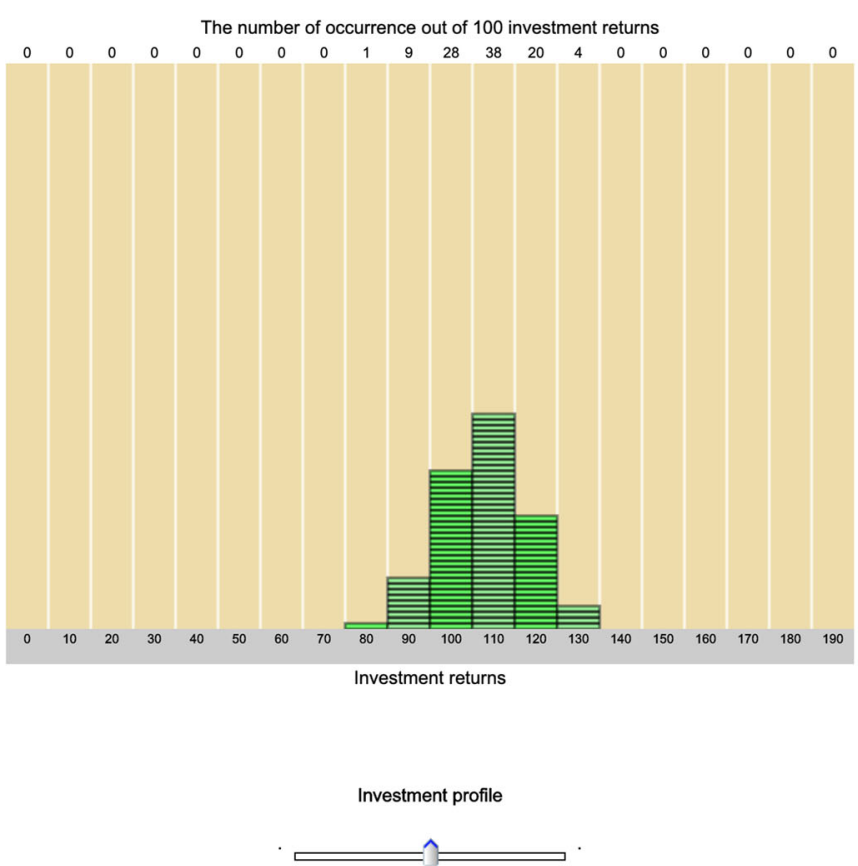

Fig. 4 Investment decisions in the separate condition of Experiment 2

\section{Results}

We find that participants selected different risks and returns in the separate condition compared to the integrated condition for both correlation conditions (see Table 2). In the nocorrelation condition, participants chose higher returns and risks in the separate condition ( $7.6 \%$ and $7.8 \%$, respectively) than they did in the integrated condition $(7.2 \%$ and $7.0 \%)$. In the positive correlation condition, participants chose lower returns and risks in the separate condition $(7.4 \%$ and $9.3 \%$, respectively) than they did in the integrated condition $(8.2 \%$ and $10.3 \%$ ) (all differences significant at $p<.01$ ). Together with the findings of Experiment 1, these results illustrate the difficulty of drawing conclusions regarding consumers performance based on the observed shifts in the risks and returns. First, it is difficult to generalize the impact of correlation on subjective risk-return preferences. This is also reflected in the literature where different findings have been reported (Anagol and Gamble 2013; Beshears et al. 2017). Second, it is not clear if observed shifts in risk-return preferences place investors' selected risk-return portfolio on or below the optimal CAL (see Fig. 3).

Therefore, we next look at the loss in returns and excessive risks that participants incurred in the separate choice condition. Interestingly, we find that the values of the loss in returns and excessive risks differ strongly between the no-correlation and positive correlation conditions (see Table 2). The results show that participants chose significantly more inefficient portfolios in the positive correlation condition (loss in returns $0.06 \%$ [no correlation] vs. $0.20 \%$ [positive correlation];
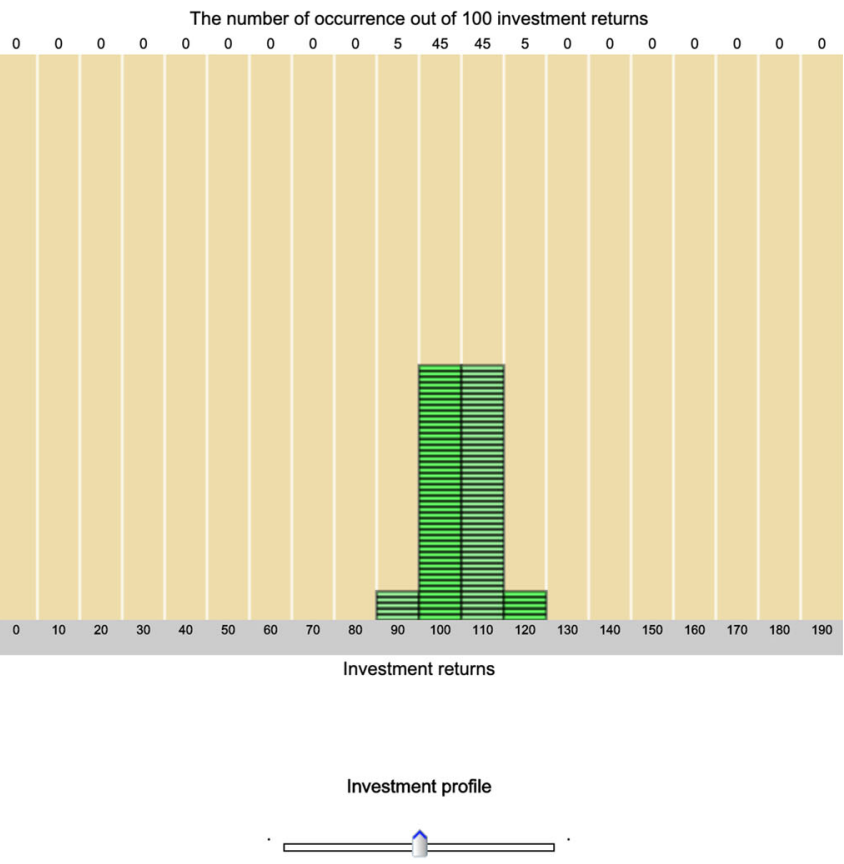

excessive risk $0.10 \%$ [no correlation] vs. $0.39 \%$ [positive correlation]; both differences are significant at $p<.01$ ).

We also analyzed how the different background variables and the two correlation conditions affected decision outcomes in two regression analyses (see Web Appendix 2 for the complete analysis results). The results further support the conclusion that the presence of correlation between investment funds strongly deteriorates consumer investors' separate decision performance. Participants choose more inefficient

Table 2 Returns and risks of participants' chosen portfolios in Experiment $2^{\S}$

\begin{tabular}{lll}
\hline & Separate & Integrated \\
\hline No correlation & & \\
Expected return $^{\mathrm{a}}$ & $7.6 \%(1.4 \%)$ & $7.2 \%(1.6 \%)$ \\
Risk $^{\mathrm{a}}$ & $7.8 \%(2.3 \%)$ & $7.0 \%(2.7 \%)$ \\
Loss in returns in separate condition $^{\mathrm{b}}$ & $0.06 \%(0.11 \%)$ & \\
Excessive risk in separate condition $^{\mathrm{b}}$ & $0.10 \%(0.19 \%)$ & \\
Positive correlation & & \\
Expected return $^{\mathrm{a}}$ & $7.4 \%(1.3 \%)$ & $8.2 \%(2.1 \%)$ \\
Risk $^{\mathrm{a}}$ & $9.3 \%(2.7 \%)$ & $10.3 \%(4.2 \%)$ \\
Loss in returns in separate condition $^{\mathrm{b}}$ & $0.20 \%(0.11 \%)$ & \\
Excessive risk in separate condition $^{\mathrm{b}}$ & $0.39 \%(0.21 \%)$ & \\
\hline
\end{tabular}

${ }^{\S} N=310$. Standard deviations in parentheses

${ }^{a}$ Values significantly different between the separate and virtually integrated conditions $(p<.01)$

${ }^{\mathrm{b}}$ Values significantly different between the no correlation and the positive correlation conditions $(\mathrm{p}<.01)$ 
portfolios with correlation, both in terms of loss in returns $(\beta=.160 ; p<.05)$ and in terms of excessive risk $(\beta=.328$; $p<.05$ ). With regard to financial literacy, as in Experiment 1, we find no effect (nor an effect of understanding or cognitive ability). However, in this experiment, we do find a small attenuating effect of higher education on inefficiency, while risk seeking leads to greater inefficiency.

\section{Discussion}

Experiment 2 provides further support for the beneficial effect of virtually integrating different investment funds on consumer investors' decision outcomes. The results of this experiment show that this effect is especially strong in the case of positive correlation between investment funds. However, we also find that when funds are not correlated, there is still a positive effect of virtual integration. Jointly, these findings show that the consequences of the behavioral effects of mental separation and correlation neglect are stronger in the positive correlation condition than in the no-correlation condition.

When we compare this finding with that of Experiment 1, we see that the positive impact of virtual integration is lower with identical risk-return distributions between funds. However, such identical distributions are unlikely to occur in real-world contexts. Therefore, we expect the findings of Experiment 2 with non-identical correlated distributions to be most relevant for marketing applications. Finally, in Experiment 2, we replicate the finding from Experiment 1 that financial literacy does not attenuate the effect of separate investment fund decisions.

\section{Experiment 3: The impact of more dissimilar investment goals and negatively correlated distributions}

The results of the first two experiments demonstrated that correlations between the distributions of investment funds affect the quality of consumers' investment decisions and that this can be overcome by virtually integrating these distributions. However, in Experiment 1 we did not find evidence for an impact of mental accounting and the goal manipulation that was employed on consumer decisions. Therefore, Experiment 3 implemented a stronger goal manipulation. In addition, this experiment extends the findings to investigate the impact of negative correlations in investment funds. ${ }^{7}$ Such negative correlations capture real-world situations, where investors attempt to hedge their risks by combining investment funds in their portfolios that will respond differently to external shocks (e.g., covering different markets or regions). As such hedges

\footnotetext{
${ }^{7}$ We thank an anonymous reviewer for suggesting this relevant additional condition.
}

typically relate to different separate investment products, virtual asset integration will be the only way to obtain a full picture of the returns on the investment portfolio.

\section{Method}

Experimental design Experiment 3 extended the previous two experiments in three important ways. Its first objective was to further test the effect of mental accounting through a stronger manipulation of consumers' investment goals. The second objective was to generalize the findings on the impact of correlated asset returns from positively correlated investment funds to the also relevant case of negatively correlated investment funds. The third, more methodological, objective was to gain more insight into the source of the benefits of virtual integration, so we also varied the extent of integration. For this purpose, we introduced a new semi-integrated condition. The experimental design was a mixed 3 (separate vs. semiintegrated vs. virtually integrated - within subjects) by 2 (no correlation vs. negative correlation - between subjects) by 3 (investment goal 1 , goal 2 , both goals 1 and 2 - between subjects) design, generating a total of 12 conditions.

The separate and virtually integrated investment fund conditions were identical to those in the first two experiments. The new semi-integrated condition involved a choice architecture where investors could make separate risk-return decisions by investment fund, but the distribution of outcomes was presented in an integrated manner (i.e., participants directly [and only] observed the visual distribution of their combined investment portfolios). The key feature of this choice architecture is that participants still made two separate decisions, but the computationally complex integration of the two distributions was performed by the tool, thereby helping consumers overcome the consequences of correlation neglect. The order of presentation of the separate, semi-integrated, and virtually integrated investment fund conditions was randomized, and all participants responded to all three conditions.

To generate stronger mental accounting differences than in Experiment 1, we relied on the findings in self-regulation theory that investors' mental separation depends on the selfregulation systems that guide their investments (Higgins 1998; Zhou and Pham 2004). Based on this insight, we connected one investment goal to a promotion goal, in the form of saving for a desirable product (i.e., a kitchen renovation), and the other to a prevention goal, in the form of repaying a loan. More specifically, participants were exposed to one of three investment goal conditions in which they were told that they were investing money for one year, to repay a loan, renovate a kitchen, or do both. Investing for a kitchen renovation is likely associated with a promotion focus aimed at achieving desirable outcomes. The investment goal of repaying a loan is likely to invoke a prevention-focused self-regulation system in order to avoid financial losses because of debt aversion 
(Prelec and Loewenstein 1998; Thaler 1990). Therefore, we anticipated that these different goals would induce a stronger tendency to mentally separate the two investments than the two investment goals of saving for a new kitchen and a new car that were employed in Experiment 1.

Regarding the correlation conditions, as in the other experiments, participants were randomly assigned to one of the two conditions. In Experiment 3, these were generated as follows: one condition involved no correlation between the two investment returns (Pearson correlation coefficient $\rho=0$ ) and one involved a negative correlation $(\rho=-0.6)$.

Participant task and customization interface As in Experiment 1, participants were asked to invest a total amount of $€ 20,000$, split equally between two investment funds. The target for each investment fund was set at $€ 9500$. This ensured that participants were not induced to take large risks to maximize the probability of meeting their investment targets. The procedure was the same as in the previous experiments, with one exception: in this experiment, participants did not receive an additional monetary reward based on their performance. Participants decided on the risk level for two investment funds with different riskreturn distributions. One investment fund had a moderately higher risk-return distribution (mean: 13\%; standard deviation: 19\%) than the other (mean: 11\%; standard deviation 15\%); see Fig. 5a. Participants received a flat reward of $€ 2.35$ for their participation.

Participants customized the risk-return distribution for their investments using the same interactive riskreturn distribution tool for the separate, semi-integrated, and integrated conditions (see Fig. 5b). As an additional dependent variable in this experiment, once participants made their final decisions in each condition, they were also asked to indicate their level of satisfaction with the resulting outcome distribution.

The same background variables were collected from participants as in Experiment 1. Given the different nature of the investment goals, participants' likelihood to treat multiple accounts as separate mental accounts was measured by asking their likelihood to transfer money from one investment to the other (on a scale from 0 to 10). This was done by asking them how willing they were to move money from the investment fund to repay the loan to the investment fund for the kitchen, as well as how willing they were to do the reverse. In addition, to gain more insight into participants' understanding of the correlations presented to them, we measured their understanding of the joint distribution as follows. Participants were shown the separate return distributions of two investment funds. They were then asked to choose the correct answer out of four options describing the joint probability distribution of the funds. Three of these answer options reflected the tail probabilities of the joint distribution corresponding to the case of no correlation, positive correlation, and negative correlation between two investment returns, respectively, with the correct answer depending on the condition the participant was assigned to. The fourth answer option was the tail probability that resulted from taking the average of the marginal probabilities across funds (rather than by properly integrating these probabilities). This latter answer option resulted in the largest tail probability and allowed us to identify participants who failed to calculate the probabilities of joint events following the basic rules of probability. Details of the questions are provided in Web Appendix 1.

Sample A sample of 1473 participants (based on a randomized assignment of participants for each between subject correlation and investment goal condition, with a target number of 250 participants per cell) were recruited in the Netherlands by a market research agency using their online panel. Respondents were largely representative of the Dutch general population, with an average age of 47.83 years old, an average annual pre-tax income tax of $€ 40,261$, and a gender distribution of $46.0 \%$ female to $54.0 \%$ male (see Appendix 1 for details).

\section{Results}

The impact of different investment goals First, participants' likelihood to transfer money from one investment fund to the fund with a different goal was examined to test whether the investment goal conditions successfully induced participants' mental separation across the different investments. We find that participants are more reluctant to transfer money invested with the prevention-focused goal of repaying a loan (mean: 4.88; standard deviation: 2.51 ) than to transfer money from the investment fund for the promotion-focused goal of saving for a kitchen (mean 6.15; standard deviation 2.52; difference significant at $p<.01)$. This shows that participants treat the two investments differently, which is in line with the anticipated association with different mental systems across the two goals. Thus, as expected, the regulatory focused-based investment goal manipulation was more effective than the one used in Experiment 1.

Next, we analyzed the effect of the different investment goal conditions on the virtual integration of funds. We anticipated that, with stronger mental separation, participants would exhibit different behaviors depending on the investment goal conditions. However, we find no significant effect of investment goals on participants' decisions nor do we find a significant interaction with the other conditions, regardless of the degree of virtual integration of the funds; this is similar to the previous two experiments. The investment goal conditions also did not significantly affect the inefficiency of portfolios that participants chose. 


\section{a Separate condition (fund by fund)}

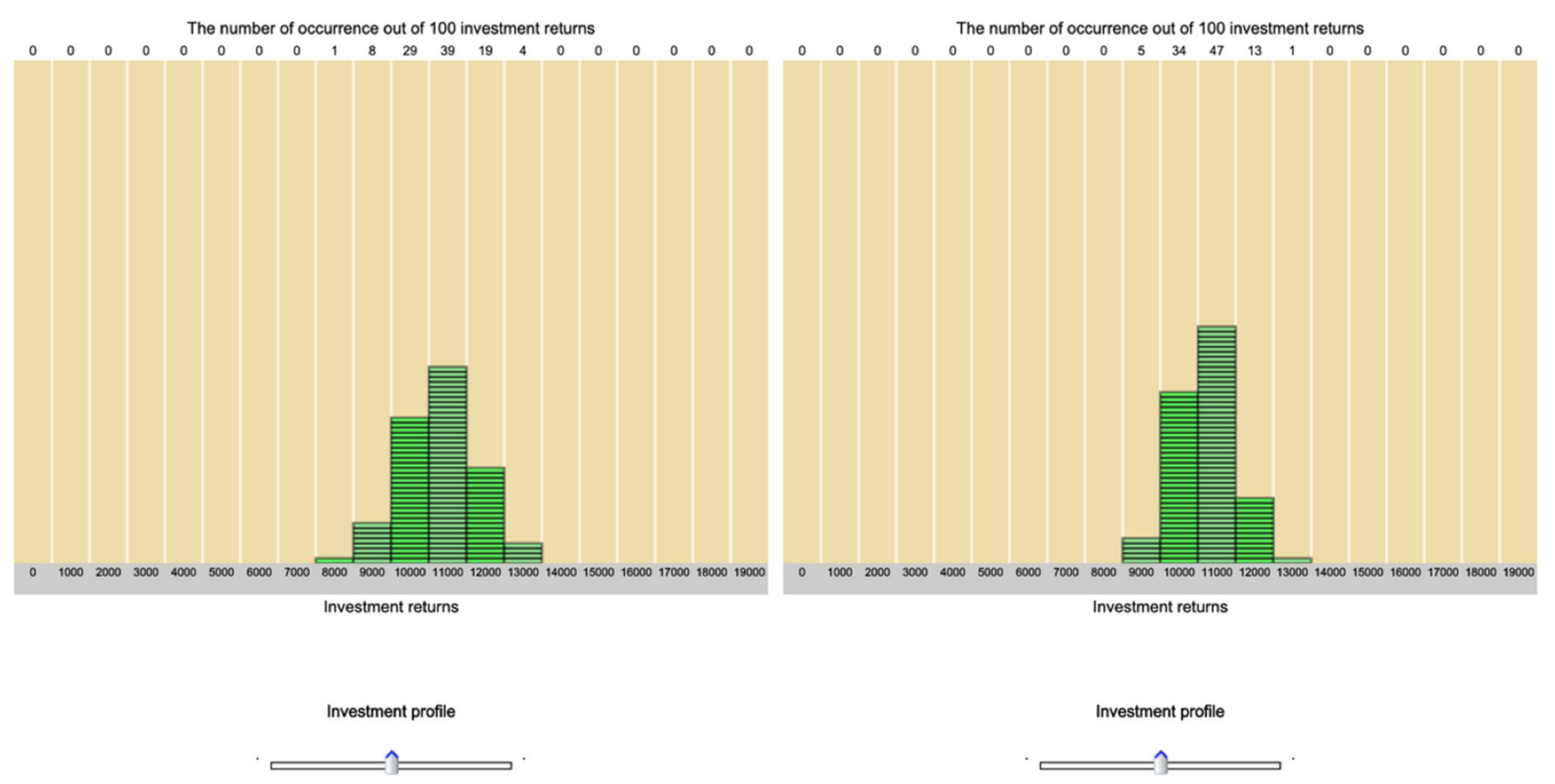

\section{b Semi-integrated condition}

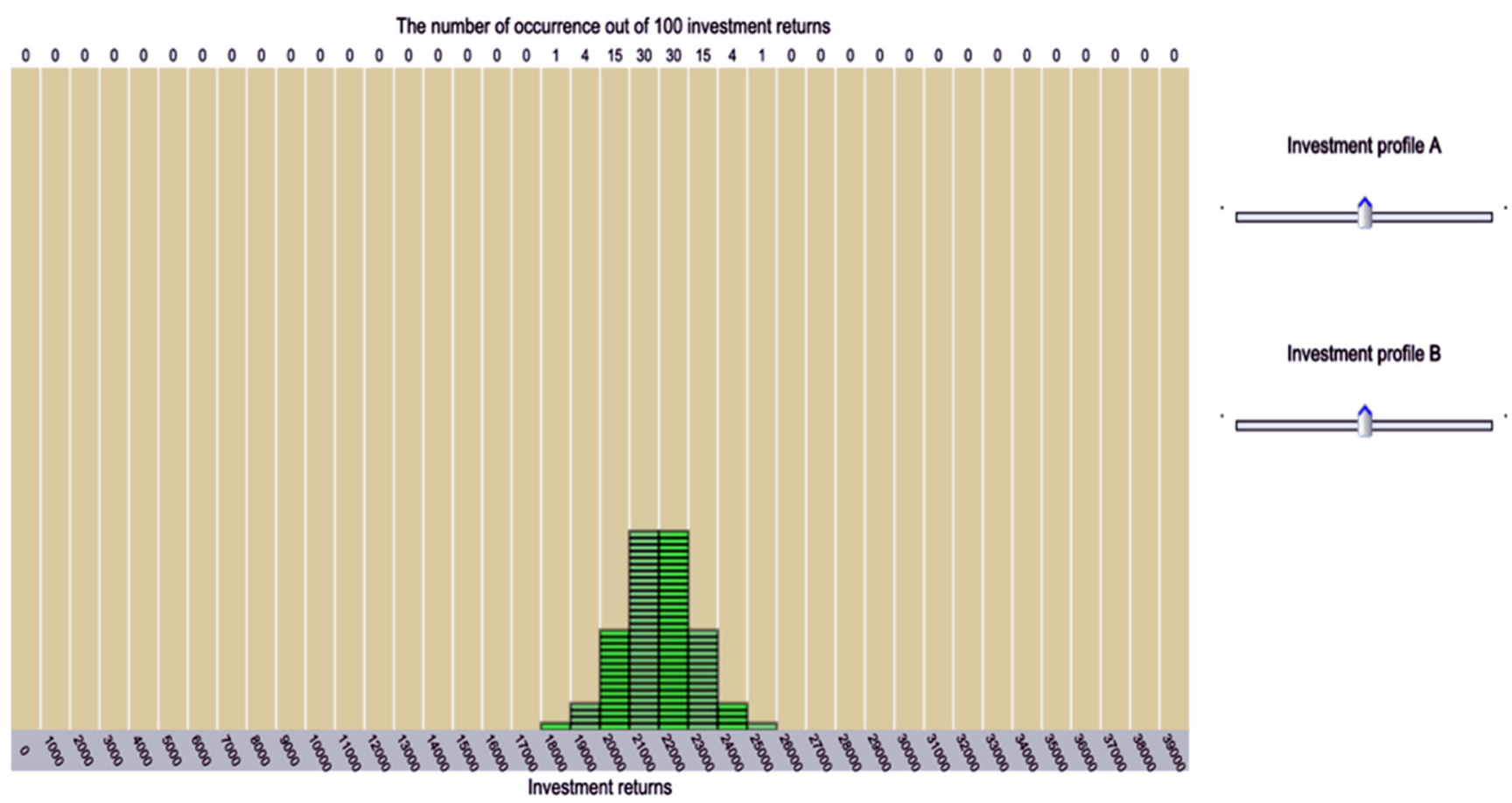

Fig. 5 Separate and semi-integrated investment decision choice architectures

The impact of virtual integration and semi-integration with negative correlations The correlation between the two funds' returns has a strong impact on the benefits of virtual integration (see Table 3). In the no-correlation condition, and averaged across the goal conditions, participants chose higher returns and risks in the separate condition (8.3\% and $7.2 \%$, respectively) than in the integrated condition $(8.0 \%$ and $6.6 \%$ ), replicating the results of Experiment 2. In the negative correlation condition, participant chose lower returns with higher risks in the separate condition $(8.1 \%$ and $4.9 \%$, 
Table 3 Returns and risks of participants' chosen portfolios in Experiment $3^{\S}$

\begin{tabular}{llll}
\hline & Separate & Semi-integrated & Integrated \\
\hline No correlation & & & \\
Expected return $^{\mathrm{a}, \mathrm{c}}$ & $8.3 \%(1.8 \%)$ & $8.0 \%(2.0 \%)$ & $8.0 \%(2.1 \%)$ \\
Risk $^{\mathrm{a}, \mathrm{b}, \mathrm{c}}$ & $7.2 \%(2.4 \%)$ & $6.9 \%(2.7 \%)$ & $6.6 \%(2.8 \%)$ \\
Loss in returns $^{\mathrm{c}}$ & $0.16 \%(0.29 \%)$ & $0.22 \%(0.34 \%)$ & \\
Excessive risk $^{\mathrm{c}}$ & $0.22 \%(0.38 \%)$ & $0.30 \%(0.46 \%)$ & \\
Negative correlation & & & \\
Expected return $^{\mathrm{a}, \mathrm{b}}$ & $8.1 \%(1.8 \%)$ & $8.2 \%(2.0 \%)$ & $8.4 \%(2.3 \%)$ \\
Risk $^{\mathrm{a}, \mathrm{b}}$ & $4.9 \%(1.7 \%)$ & $5.0 \%(1.9 \%)$ & $4.5 \%(1.9 \%)$ \\
Loss in returns & $0.62 \%(1.06 \%)$ & $0.72 \%(1.17 \%)$ & \\
Excessive risk & $0.53 \%(0.89 \%)$ & $0.61 \%(0.99 \%)$ & \\
\hline
\end{tabular}

${ }^{\S} N=1473$. Standard deviations in parentheses. Table presents average values over three investment goal conditions

${ }^{a}$ Values significantly different between the separate and virtually integrated conditions $(\mathrm{p}<.05)$

${ }^{\mathrm{b}}$ Values significantly different between the semi-integrated and virtually integrated conditions $(\mathrm{p}<.05)$

${ }^{c}$ Values significantly different between the separate and the semiintegrated conditions $(\mathrm{p}<.05)$

respectively) than in the integrated condition ( $8.4 \%$ and $4.5 \%$; all differences are significant at $p<.01)$. This shows that virtual integration is beneficial and provides individuals with higher expected returns at lower risk levels. This is also reflected in a significant impact of correlation on the loss in returns and excessive risks that participants incurred in the separate choice condition. Participants chose significantly less efficient portfolios in the negative correlation condition (loss in returns $0.62 \%$ and excessive risk $0.53 \%$ ) than in the no-correlation condition (loss in returns $0.16 \%$ and excessive risk $0.22 \%$; differences between both aspects are significant at $p<.01)$.

Next, turning to participants' decisions in the new semi-integrated condition, we find that they selected returns and risks closer to those in the integrated condition than in the separate condition. Specifically, the average returns and risks of the selected portfolios were $8.0 \%$ and $6.6 \%$ for the no-correlation condition and $8.2 \%$ and $5.0 \%$ for the negative correlation condition. However, the effect of (fully) integrating the distributions is still beneficial compared to the semi-integrated condition. In fact, participants chose significantly less efficient portfolios when observing the integrated distribution of the two funds rather than the separate distributions. The loss in returns and excessive risk in the semi-integrated, no-correlation condition were $0.22 \%$ and $0.30 \%$, respectively, and $0.72 \%$ and $0.61 \%$ for the semi-integrated, negative correlation condition, which are both larger $(p=.00$ for the no-correlation; $p=.06$ for the negative correlation) than in the separate condition. Therefore, helping consumer investors by integrating the distributions, but still requiring them to make separate choices, is not sufficient to enable them to compose fully efficient investment portfolios.

We also conducted a regression analysis to investigate how the inefficiency of investors' decisions depends on the different experimental conditions. The results replicate our earlier findings in Experiments 1 and 2, proving robustness to the different goals and correlation levels. Participants choose more inefficient portfolios with correlation, both in terms of loss in returns $(\beta=.060, p<.05)$ and excessive risks $(\beta=.041, p<.05)$. Also, we find no effect of the background variables we measured, including financial literacy, stated risk preference, and cognitive ability, which is similar to Experiments 1 and 2. We provide the full results in Web Appendix 2. Additionally, we analyzed an order variable indicating whether participants saw the separate condition first or one of the integrated conditions. We find no significant effect of order and the other findings remain unchanged.

Finally, we analyzed whether participants were able to understand the correlation between the fund returns or integrate the distributions themselves, and we studied their satisfaction with the resulting distribution. We find that, even though participants received an explanation of the correlation between the investment returns and also experienced at least 10 samples from the joint return distribution, their correlation perceptions did not vary with the level of correlation. More specifically, when asked about a directional prediction of one investment fund's return given the return on the second fund, about $60 \%$ of participants report a positive relationship between the investment returns, whereas the actual correlations were zero or negative ( $p=.71$ when testing the association with correlation conditions). Moreover, for the questions on the tail probabilities of the joint distribution, the three answers that correspond to no correlation, positive correlation, and negative correlation, were chosen by $34 \%, 28 \%$, and $22 \%$ of participants, respectively. The remaining $16 \%$ of participants selected a tail probability that is so large that it is impossible, even with perfectly correlated asset returns. Hence, participants are rather poor in determining the joint distribution, and their answers did not even differ across the two correlation conditions $(p=.35)$.

Regarding decision outcome satisfaction, participants were more satisfied with the resulting investment fund risk-return distribution in the virtually integrated condition (mean: 5.45; standard deviation: 1.04) than in the semi-integrated (mean: 5.40; standard deviation: 1.10; difference with the integrated condition: $p<.01$ ) and separate (mean: 5.25 ; standard deviation: 1.14; difference with the integrated condition: $p<.01$ ) conditions. The semi-integrated interface also resulted in higher satisfaction levels than the tool with separate distributions $(p<.01)$. 


\section{Discussion}

Experiment 3 provides consistent evidence on the effect of virtual integration of investment funds on consumer investors' decisions. We find the properties of the joint distribution of the asset returns to be a more impactful driver than the mental separation resulting from different investment goals. The latter holds even under the stronger manipulation of mental separation of investment goals in this experiment. An important finding is that, when asked about their ideas about the integrated distributions, participants' answers are more reflective of a positive correlation between the two investment funds and are not affected by correlation information. This suggests that it might not be correlation neglect-resulting in independent, uncorrelated distributions - but some other heuristic or decision rule being implemented. Such an insensitivity to correlation information could also explain why the $1 / \mathrm{N}$ heuristic is such a prevalent portfolio allocation heuristic.

The detrimental effect of an incorrect integration of the two separate distributions can be resolved by presenting integrated risk-return distributions, which we implemented in the semi-integrated condition. However, we still find substantial inefficiencies remaining in the portfolio decisions, which are resolved through virtual integration of the investment funds. Virtual integration of investment funds hence benefits consumer investors both objectively-as it results in more efficient investment portfolios-and subjectively-as it increases their satisfaction with the outcome of the process.

\section{General discussion}

Digital technology in financial services, while helping consumers gain direct access to investment funds, also creates new challenges because consumers may make suboptimal investment decisions. In three experiments, we addressed the challenge that consumers often face complex investment decisions involving multiple funds, each with their own riskreturn distribution. In each experiment, we test and find support, based on a well-defined objective outcome criterion, for the proposed positive impact of virtual integration of multiple investment funds on consumer investment decision outcomes. This positive impact occurs even though consumers use helpful interactive investment risk-return distributions for their separate choices.

We proposed two behavioral decision effects, mental separation and correlation neglect, that can occur when consumers invest in multiple funds. Our experiments show a strong impact of correlation among the asset returns on the quality of the decisions, and that it is especially strong in the realistic case of investment funds with different risk-return distributions. One potential driver of this large impact could be the use of simple decision heuristics, similar to the naive diversification heuristic where all assets receive equal weights. When asked to select their preferred risk levels, a symmetric treatment would lead consumer investors to select the same risk level for each asset, independent of the impact of each fund on the distribution of the portfolio returns. Indeed, a substantial portion of respondents in all three experiments (about 30\% for each) put both sliders in a similar position. Although this naive decision strategy composes fairly efficient portfolios when the funds are similar and uncorrelated, it results in rather inefficient portfolios when funds have different yet correlated return distributions. This can be a potential explanation for the less efficient decisions of participants in the semi-integrated condition compared to the fully integrated decision in Experiment 3 . Virtual integration of funds helps investors to construct efficient investment portfolios, independent of the source of the inefficiencies. When investments concern different asset classes, these inefficiencies are likely to be larger, and the benefits of virtual integration will increase.

Another noteworthy finding is the absence of a relationship between financial literacy and the quality of consumers' portfolio composition. This underlines the fact that even expert consumer investors can benefit from the proposed virtual integration of investment funds.

\section{Theoretical implications}

Our research adds to previous research on consumer investment decisions with multiple funds in three ways. First, where earlier research focused on shifts in (subjective) investor riskreturn preferences between separate and integrated risk-return distributions (Anagol and Gamble 2013; Beshears et al. 2017), we show that investor decision outcome quality is lower in separate distributions using an objective performance benchmark. We proposed two behavioral decision effects that can lower consumer decision outcomes when investing in multiple funds: mental separation (Brendl et al. 1998; Shefrin and Statman 2000; Thaler 1985; Zhou and Pham 2004) and correlation neglect (Enke and Zimmermann 2019; Eyster and Weizsäcker 2016; Kallir and Sonsino 2009; Levy and Razin 2015).

Even though we find that consumers treat investment accounts asymmetrically when they are linked to different goals - in our case, repaying a loan or renovating a kitchen - the quality of the composed portfolios is not worse when the accounts relate to multiple goals instead of a single shared goal. Regarding correlation neglect, our results confirm 
previous research showing that people are not responsive to correlation information; see, for example, Kroll et al. (1988). More recent research has termed this "correlation neglect" (i.e., Kallir and Sonsino 2009). More direct measures on the inferred integrated distribution, however, suggest that our respondents generally perceive a positive correlation among the different assets. They do not then seem to update their beliefs about the correlation between the asset returns when they are provided with information, either written or through experiencing draws from the joint distribution. This inability to account for different levels of correlations among assets is consistent with the frequent use of the $1 / \mathrm{N}$ heuristic observed in many other asset allocation decisions (Benartzi and Thaler 2001), even among experts (Fernandes 2013).

igital support through virtual integration of multiple funds is a fruitful new choice architecture that helps overcome the harmful behavioral effects in investment decisions with multiple funds. To date, no research had explored how to alleviate the problems arising when decisions on correlated assets need to be made (Laudenbach et al. 2017). Our approach extends, for the first time, insights from mass-customization for traditional products to the financial services domain to meet this need (Randall et al. 2005; Von Hippel and Katz 2002). We also studied whether more financially literate consumers are better able to compose efficient investment portfolios. Our findings show that this is not the case and that virtual integration of multiple investment funds is beneficial for consumers, irrespective of their financial literacy levels.

\section{Managerial implications}

Our findings clearly suggest that investment firms can help consumer investors by virtually integrating investment funds on their online investment platforms. Our experiments show that participants had difficulty integrating multiple funds, even when using an advanced interactive risk-return tool that allowed them to observe the risk-return profile of each separate fund side by side. This finding implies that putting the risk-return information of all the funds that an investor owns (or considers investing in) side by side on a platform is not sufficient to support consumer investors' decisions involving multiple funds. Because investors tend to fail to accurately incorporate correlations among investment funds, it is almost impossible for them to construct efficient investment portfolios of multiple funds when they need to make investment decisions across different asset classes. Therefore, investment firms can substantially improve their service levels when providing their customers the opportunity to determine their preferred risk-return profiles using a single integrated portfolio approach by virtually integrating the funds investors can invest in. The fact that consumes are also more satisfied with the resulting risk-return distribution (see Experiment 3) is also positive in this respect since it can promote adoption by consumers, which in turn makes it more attractive for firms to offer this service as well.

As virtual integration tools also automatically mix the underlying risky assets, investors can achieve substantial benefits by avoiding mistakes in choosing inefficient portfolios. Based on our empirical results, we can simulate the financial losses of a representative investor who invests $€ 100,000$ in two funds while incurring the average portfolio inefficiencies observed in Experiment 2. Assuming that the return distributions of the two funds are also as specified in Experiment 2 and positively correlated, the investor would incur a loss of $€ 200$ in the first year, increasing to $€ 1310$ after five years. Also, as the investor tends to take excessive risks, the probability of losing money is increased by $1 \%$ compared to the optimal integrated portfolio choice. Losses are even larger in the investment scenario used in Experiment 3, where a representative investor would lose $€ 620$ in the first year and $€ 4320$ after five years, and the probability of losing money would increase by $1.7 \%$. This clearly shows the substantial benefits of consumer investors customizing their preferred risk-return profiles in virtually integrated portfolios using an interactive simulation tool, rather than customizing their preferred riskreturn profiles for each investment fund separately. Virtual integration generates real monetary value for customers and increased customer satisfaction for a firm that offers virtually integrated choice architectures. Virtual integration of funds, therefore, seems to be one way for financial services firms to seize the opportunities identified by Brodsky and Oakes (2017) to achieve improved customer experience, new revenue streams, and a sustainable service model for an underserved market. The fact that these benefits arise, irrespective of consumer investors' financial literacy, suggests that the market reach of such a new digital offering could be large.

\section{Limitations and future research}

This research also has some inherent limitations. First, even though we included two incentive-aligned experiments and all studies were based on general population samples, the decisions participants made were still hypothetical. Therefore, it would be valuable if the proposed new choice architecture could also be tested in a financial firm's actual digital environment. This would provide further external validation for the findings. Along similar lines, it would be interesting to see if the effect sizes found in the experiments are aggravated if consumer investors use risk-return tasks that are currently still more common in practice, such as single question risk-return allocation decisions or the multiple lottery choice method (Alserda et al. 2019; Dohmen et al. 2011; Holt and Laury 2002). We anticipate that these more traditional, non-visual 
and less experience-oriented interfaces will strengthen the observed biases and, therefore, lower consumer decision outcomes when investing in multiple funds.

In addition, although we did not consider reinvestment opportunities, investors might gain additional benefits from the virtual integration of funds when they engage in (periodic) rebalancing their long-term investment portfolios. Future research could study whether virtual integration can also improve such rebalancing decisions, for example, by weakening investors' reluctance to sell individual assets at a loss (Odean 1998). Moreover, with clear and specific information on the desired risk-return profile of their investors, investors might also be willing to delegate the required rebalancing decisions to the firm.

Future research could also address in more detail what underlying cognitive processes drive the hypothesized behavioral effects of mental accounting and correlation neglect. In line with previous work, our research has addressed these phenomena in terms of the behavioral shifts that can be observed in consumer decision outcomes. However, it would also be interesting to study the cognitive processes that generate these behaviors. For example, correlation neglect may stem from different processing strategies that consumers employ in making decisions (e.g., simplifying assumptions with respect to correlations), but it may also stem from limitations in consumers' cognitive capacity that lead them to focus on certain aspects of the decision task while ignoring the aspect of correlation all together. Consumers naïve beliefs about diversification may be one plausible explanation for why semiintegrated presentation still leads to lower quality decisions than fully integrated presentation (Fernandes 2013; Gubaydullina and Spiwoks 2015).

A practical limitation to the proposed new choice architecture of virtual integration can be that financial firms may not have access to the risk-return information for all funds that a consumer investor owns. For example, a consumer's current investment fund may not know if a consumer is also investing in another fund, or if the fund does know, it may not know the riskreturn level of the investments in the other fund. This lack of cross-fund data availability may hinder the virtual integration of investment funds in practice. However, it also opens up opportunities for financial service intermediaries to create value for consumers by integrating risk-return information over multiple funds. In some countries (e.g., the Netherlands) and for some types of investments (i.e., pensions), governments are already actively promoting data integration in publicprivate platforms; this can further assist consumers. Regulation that requires financial firms to share investment data with other financial services providers, if their customers request them to do so, such as Europe's Payment Services Directive (PSD2; European
Union 2015) or the UK's Open Banking Initiative (Open Banking Working Group 2017), are creating the institutional environment to support a flourishing financial integration services market. These developments provide a large and promising area for future research.

Finally, in our experiments, we studied decisions involving one-shot decisions for two very similar types of investments. In reality, consumer investors may hold even more complex portfolios, including a variety of different financial assets that they can rebalance over time. For example, consumers may have a regular savings account, own their own home, expect an inheritance, and plan to pay off part of their mortgage, all in addition to investing in funds. It would be interesting to further extend our research into these even more complex settings and to begin to develop integration tools that could assist consumer investors in optimizing their financial decisions over the complex reality of multiple assets of multiple types. We hope our research can offer a first step in further developing this societally important area for digital consumer decision support.

Acknowledgments This research has received financial support from Netspar (Network for Studies on Pension, Aging,and Retirement) and ERIM (Erasmus Research Institute in Management).

\section{Appendix 1: Descriptive Statistics for Experiments}

Table 4 Descriptive statistics participants Experiment 1

\begin{tabular}{ll}
\hline & Values \\
\hline Number of participants & 598 \\
Age & $47.84 \pm 19.07$ \\
Annual income & $37,318 \pm 58,868$ \\
Male & $276(46.2 \%)$ \\
Level of education & \\
Primary school & $16(2.7 \%)$ \\
High school & $153(25.6 \%)$ \\
Secondary vocational education & $174(29.1 \%)$ \\
Bachelor's degree or higher & $255(42.6 \%)$ \\
Understanding (Min. 0; Max. 4) & $2.30 \pm 1.11$ \\
Cognitive ability (Min. 0; Max. 3) & $0.82 \pm 1.01$ \\
Financial literacy (Min. 0; Max. 4) & $2.39 \pm 1.15$ \\
Risk preference (Min.1; Max. 5.5) & $2.87 \pm 1.04$ \\
Awareness of the correlation & $418(69.9 \%)$ \\
Formatting combined mental accounts (Min. 0; Max. & $6.06 \pm 2.63$ \\
10) & \\
\hline
\end{tabular}

${ }^{\mathrm{a}}$ Correlation between two items $=0.642 ;$ Cronbach alpha $=0.782$ 
Table 5 Descriptive statistics participants Experiment 2

\begin{tabular}{lll}
\hline & No correlation & Positive correlation \\
\hline Number of participants & 152 & 158 \\
Age & $45.11 \pm 14.19$ & $48.27 \pm 14.06$ \\
Annual income & $39,094 \pm 22,807$ & $45,089 \pm 37,493$ \\
Male & $68(45 \%)$ & $90(57 \%)$ \\
Schooling & & \\
Primary school & $3(2.0 \%)$ & $2(1.3 \%)$ \\
High school & $44(29.0 \%)$ & $57(36.1 \%)$ \\
Secondary vocational education & $51(33.6 \%)$ & $47(29.8 \%)$ \\
Bachelor's degree or higher & $54(35.5 \%)$ & $52(32.9 \%)$ \\
Financial literacy (Min. 0; Max 4) & $2.82 \pm 1.07$ & $2.87 \pm 1.11$ \\
Understanding (Min. 0; Max 4) & $2.08 \pm 0.99$ & $2.26 \pm 0.92$ \\
Cognitive ability (Min. 0; Max 3) & $1.05 \pm 1.10$ & $1.21 \pm 1.12$ \\
Risk preference (Min.1; Max. 5.5) & $3.09 \pm 0.91$ & $3.15 \pm 0.97$ \\
\hline
\end{tabular}

${ }^{\mathrm{a}}$ Correlation between two items $=0.69 ;$ Cronbach alpha $=0.82$

Table 6 Descriptive statistics participants Experiment 3

\begin{tabular}{|c|c|c|c|c|c|c|}
\hline \multirow{2}{*}{$\begin{array}{l}\text { Goal } \\
\text { Correlation }\end{array}$} & \multicolumn{2}{|l|}{ Kitchen } & \multicolumn{2}{|l|}{ Loan } & \multicolumn{2}{|l|}{ Multiple goals } \\
\hline & No & Negative & No & Negative & No & Negative \\
\hline Number of participants & 244 & 260 & 245 & 239 & 244 & 241 \\
\hline Age & $47.9 \pm 16.9$ & $47.9 \pm 17.1$ & $47.6 \pm 17.8$ & $48.0 \pm 16.4$ & $48.4 \pm 18.2$ & $47.2 \pm 16.9$ \\
\hline Income & $46,265 \pm 74,191$ & $39,559 \pm 68,843$ & $37,942 \pm 52,635$ & $37,624 \pm 41,533$ & $44,326 \pm 78,001$ & $35,779 \pm 43,617$ \\
\hline Male & $126(52 \%)$ & $133(51 \%)$ & $146(60 \%)$ & $133(56 \%)$ & $141(58 \%)$ & $117(49 \%)$ \\
\hline \multicolumn{7}{|l|}{ Schooling } \\
\hline Primary & $0(0 \%)$ & $5(2 \%)$ & $9(4 \%)$ & $0(0 \%)$ & $2(1 \%)$ & $1(0 \%)$ \\
\hline High school & $42(17 \%)$ & $53(20 \%)$ & $33(14 \%)$ & $42(18 \%)$ & $43(18 \%)$ & $46(19 \%)$ \\
\hline Secondary vocational education & $63(26 \%)$ & $78(30 \%)$ & $77(31 \%))$ & $70(29 \%)$ & $75(31 \%)$ & $66(27 \%)$ \\
\hline Bachelor's degree or higher & $139(57 \%)$ & $124(48 \%)$ & $126(51 \%)$ & $127(53 \%)$ & $124(51 \%)$ & $128(54 \%)$ \\
\hline Understanding (Min. 0; Max 4) & $2.59 \pm 1.12$ & $2.40 \pm 1.03$ & $2.44 \pm 1.22$ & $2.53 \pm 1.11$ & $2.51 \pm 1.15$ & $2.63 \pm 1.08$ \\
\hline Cognitive ability (Min. 0 ; Max 3) & $1.06 \pm 1.05$ & $1.09 \pm 1.11$ & $1.17 \pm 1.10$ & $1.03 \pm 1.11$ & $1.02 \pm 1.08$ & $1.09 \pm 1.11$ \\
\hline Financial literacy (Min. 0; Max 4) & $2.51 \pm 1.15$ & $2.44 \pm 1.15$ & $2.54 \pm 1.11$ & $2.58 \pm 1.16$ & $2.49 \pm 1.17$ & $2.59 \pm 1.17$ \\
\hline Risk preference $^{\mathrm{a}}$ (Min. 1 ; Max 5) & $2.93 \pm 1.08$ & $2.86 \pm 1.03$ & $2.95 \pm 1.07$ & $2.95 \pm 1.11$ & $2.98 \pm 0.98$ & $2.86 \pm 0.97$ \\
\hline Awareness of correlation & $78(32 \%)$ & $41(16 \%)$ & $60(24 \%)$ & $42(18 \%)$ & $64(26 \%)$ & $25(10 \%)$ \\
\hline $\begin{array}{l}\text { Formatting combined mental accounts for } \\
\text { kitchen (Min. 0; Max 10) }\end{array}$ & $4.99 \pm 2.65$ & $5.26 \pm 2.35$ & $4.79 \pm 2.45$ & $4.85 \pm 2.52$ & $4.85 \pm 2.47$ & $4.51 \pm 2.58$ \\
\hline $\begin{array}{l}\text { Formatting combined mental accounts for } \\
\quad \text { loan (Min. 0; Max 10) }\end{array}$ & $6.40 \pm 2.65$ & $6.05 \pm 2.42$ & $5.77 \pm 2.55$ & $6.00 \pm 2.59$ & $6.15 \pm 2.42$ & $6.56 \pm 2.43$ \\
\hline
\end{tabular}

${ }^{\text {a }}$ Correlation between two items $=0.65 ;$ Cronbach alpha $=0.79$ 
Open Access This article is licensed under a Creative Commons Attribution 4.0 International License, which permits use, sharing, adaptation, distribution and reproduction in any medium or format, as long as you give appropriate credit to the original author(s) and the source, provide a link to the Creative Commons licence, and indicate if changes were made. The images or other third party material in this article are included in the article's Creative Commons licence, unless indicated otherwise in a credit line to the material. If material is not included in the article's Creative Commons licence and your intended use is not permitted by statutory regulation or exceeds the permitted use, you will need to obtain permission directly from the copyright holder. To view a copy of this licence, visit http://creativecommons.org/licenses/by/4.0/.

\section{References}

Alserda, G. A., Dellaert, B. G. C., Swinkels, L., \& van der Lecq, F. S. (2019). Individual pension risk preference elicitation and collective asset allocation with heterogeneity. Journal of Banking \& Finance, 101, 206-225.

Anagol, S., \& Gamble, K. J. (2013). Does presenting investment results asset by asset lower risk taking? Journal of Behavioral Finance, 14(4), 276-300.

Barber, B. M., \& Odean, T. (2001). The internet and the investor. Journal of Economic Perspectives, 15(1), 41-54.

Bateman, H., Eckert, C., Geweke, J., Louviere, J., Satchell, S., \& Thorp, S. (2016). Risk presentation and portfolio choice. Review of Finance, 20(1), 201-229.

Benartzi, S., Thaler, R.H. (2001) Naive Diversification Strategies in Defined Contribution Saving Plans. American Economic Review, 91(1), 79-98

Beshears, J., Choi, J. J., Laibson, D., \& Madrian, B. C. (2017). Does aggregated returns disclosure increase portfolio risk taking? Review of Financial Studies, 30(6), 1971-2005.

Blume, M. E., \& Friend, I. (1975). The asset structure of individual portfolios and some implications for utility functions. The Journal of Finance, 30(2), 585-603.

Brendl, C. M., Markman, A. B., \& Higgins, E. T. (1998). Mental accounting as self-regulation: Representativeness to goal-derived categories. Zeitschrift Fur Sozialpsychologie, 29(2), 89-104.

Brodsky, L., \& Oakes, L., 2017. Data sharing and open banking. McKinsey \& Company, September 2017. Retrieved March 29, 2020 from https://www.mckinsey.com/industries/financialservices/our-insights/data-sharing-and-open-banking.

Campbell, J. Y. (2016). Restoring rational choice: The challenge of consumer financial regulation. American Economic Review, 106(5), 130.

Dellaert, B. G. C., \& Stremersch, S. (2005). Marketing mass-customized products: Striking a balance between utility and complexity. Journal of Marketing Research, 42(2), 219-227.

Dohmen, T., Falk, A., Huffman, D., Sunde, U., Schupp, J., \& Wagner, G. G. (2011). Individual risk attitudes: Measurement, determinants, and behavioral consequences. Journal of the European Economic Association, 9(3), 522-550.

Donkers, B., Lourenço, C., Goldstein, D., \& Dellaert, B. (2013). Building a distribution builder: Design considerations for financial investment and pension decisions, netspar design paper 20. Tilburg: Netspar.

Dorn, D., \& Huberman, G. (2005). Talk and Action: What Individual Investors Say and What They Do. Review of Finance, 9(4), 437-481

Enke, B., \& Zimmermann, F. (2019). Correlation neglect in belief formation. The Review of Economic Studies, 86(1), 313-332.
European Union, 2015. Directive 2015/2366 of the European Parliament and of the Council of 25 November 2015 on payment services in the internal market, amending Directives 2002/65/EC, 2009/110/EC and 2013/36/EU and Regulation (EU) No 1093/2010, and repealing Directive 2007/64/EC. Official journal of the European Union L337/35. Retrieved March 29, 2020 from https://eur-lex.europa.eu/ legal-content/EN/TXT/?uri=CELEX:32015L2366

Eyster, E., \& Weizsäcker, G., 2016. Correlation neglect in portfolio choice: Lab evidence. Available at SSRN 2914526.

Fagerlin, A., Zikmund-Fisher, B. J., \& Ubel, P. A. (2011). Helping patients decide: Ten steps to better risk communication. Journal of the National Cancer Institute, 103(19), 1436-1443.

Fernandes, D. (2013). The 1/N rule revisited: Heterogeneity in the Naïve diversification Bias. International Journal of Research in Marketing, 30(3), 310-313.

Fernandes, D., Lynch Jr., J. G., \& Netemeyer, R. G. (2014). Financial literacy, financial education, and downstream financial behaviors. Management Science, 60(8), 1861-1883.

Franke, N., Schreier, M., \& Kaiser, U. (2010). The "I designed it myself" effect in mass customization. Management Science, 56(1), 125-140.

Goldstein, D. G., Johnson, E. J., \& Sharpe, W. F. (2008). Choosing outcomes versus choosing products: Consumer-focused retirement investment advice. Journal of Consumer Research, 35(3), 440-456.

Gubaydullina, Z., \& Spiwoks, M. (2015). Correlation neglect, naïve diversification, and irrelevant information as stumbling blocks for optimal diversification. Journal of Finance and Investment Analysis, 4(2), 1-19.

Higgins, T. E. (1998). Promotion and prevention: Regulatory focus as a motivational principle. In M. P. Zanna (Ed.), Advances in experimental psychology (Vol. 30, pp. 1-46). San Diego: Academic Press.

Holt, C. A., \& Laury, S. K. (2002). Risk aversion and incentive effects. American Economic Review, 92(5), 1644-1655.

Kallir, I., \& Sonsino, D. (2009). The neglect of correlation in allocation decision. Southern Economic Journal, 75(4), 1045-1066.

Kaufmann, C., \& Weber, M. (2013). Sometimes less is more-The influence of information aggregation on investment decisions. Journal of Economic Behavior \& Organization, 95, 20-33.

Kaufmann, C., Weber, M., \& Haisley, E. C. (2013). The role of experience sampling and graphical displays on one's investment risk appetite. Management Science, 59(2), 323-340.

Kroll, Y., Levy, H., \& Rapoport, A. (1988). Experimental tests of the separation theorem and the capital asset pricing model. American Economic Review, 78(3), 500-519.

Laudenbach, C., Ungeheuer, M., \& Weber, M. (2017). How to alleviate correlation neglect? (December 2017). Available at SSRN: https:// ssrn.com/abstract $=3086722$

Levy, G., \& Razin, R. (2015). Correlation neglect, voting behavior, and information aggregation. American Economic Review, 105(4), 1634-1645.

Lusardi, A., \& Mitchell, O. S. (2017). How ordinary consumers make complex economic decisions: Financial literacy and retirement readiness. Quarterly Journal of Finance, 7(03), 1750008.

Lusardi, A., Mitchell, O. S., \& Curto, V. (2010). Financial literacy among the young. Journal of Consumer Affairs, 44(2), 358-380.

Markowitz, H. M. (1952). Portfolio selection. Journal of Finance, 7(1), 77-91.

Odean, T. (1998). Are investors reluctant to realize their losses? The Journal of Finance, 53, 1775-1798.

Open Banking Working Group. (2017). The Open Banking Standard. Retrieved March 29, 2020 from https://www.paymentsforum.uk/ sites/default/files/documents/Background\%20Document\%20No.\% 202\%20-\%20The\%20Open\%20Banking\%20Standard\%20-\% 20Full\%20Report.pdf

Prelec, D., \& Loewenstein, G. (1998). The red and the black: Mental accounting of savings and debt. Marketing Science, 17(1), 4-28. 
Randall, T., Terwiesch, C., \& Ulrich, K. T. (2005). Principles for user design of customized products. California Management Review, 47(4), 68-85.

Sarin, R. K., \& Weber, M. (1993). Risk-value models. European Journal of Operational Research, 70, 135-149.

Schrass, D., \& Bogdan, M. (2018). Profile of mutual fund shareholders, 2018. ICI research report (December). Washington, DC: Investment Company Institute. Available at www.ici.org/pdf/rpt_18_profiles. pdf.

Sedlmeier, P., \& Gigerenzer, G. (2001). Teaching Bayesian reasoning in less than two hours. Journal of Experimental Psychology General, $130,380-400$.

Sharpe, W.F. (1966). Mutual Fund Performance. The Journal of Business, 39(1), 119-138.

Shefrin, H., \& Statman, M. (2000). Behavioral portfolio theory. Journal of Financial and Quantitative Analysis, 35(2), 127-151.

Shiller, R. (2018). Stock Market data. Available at http://www.econ.yale. $\mathrm{edu} / \sim$ shiller/data.htm.

Siebenmorgen, N., \& Weber, M. (2003). A behavioral model for asset allocation. Financial Markets and Portfolio Management, 17(1), 15-42.

Sussman, A. B., \& O'Brien, R. L. (2016). Knowing when to spend: Unintended financial consequences of earmarking to encourage savings. Journal of Marketing Research, 53(5), 790-803.

Thaler, R. (1985). Mental accounting and consumer choice. Marketing Science, 4(3), 199-214.
Thaler, R. (1990). Anomalies: Saving, fungibility, and mental accounts. Journal of Economics Perspectives, 4(1), 193-205.

Tobin, J. (1958). Liquidity preference as behavior towards risk. Review of Economic Studies, 25(2), 65-86.

Van Rooij, M. C., Kool, C. J., \& Prast, H. M. (2007). Risk-return preferences in the pension domain: Are people able to choose? Journal of Public Economics, 91(3-4), 701-722.

Van Rooij, M., Lusardi, A., \& Alessie, R. (2011). Financial literacy and stock market participation. Journal of Financial Economics, 101(2), 449-472.

Von Hippel, E., \& Katz, R. (2002). Shifting innovation to users via toolkits. Management Science, 48(7), 821-833.

Wang, G. J., Xie, C., \& Stanley, H. E. (2018). Correlation structure and evolution of world stock markets: Evidence from Pearson and partial correlation-based networks. Computational Economics, 51(3), 607635.

Weber, E. U., Siebenmorgen, N., \& Weber, M. (2005). Communicating asset risk: How name recognition and the format of historic volatility information affect risk perception and investment decisions. Risk Analysis: An International Journal, 25(3), 597-609.

Zhou, R., \& Pham, M. T. (2004). Promotion and prevention across mental accounts: When financial products dictate consumers \& investment goals. Journal of Consumer Research, 31(1), 125-135.

Publisher's note Springer Nature remains neutral with regard to jurisdictional claims in published maps and institutional affiliations. 